\title{
Give and Take: Syntactic Priming during Spoken Language Comprehension
}

\section{Citation}

Thothathiri, Malathi, and Jesse Snedeker. 2008. Give and take: Syntactic priming during spoken language comprehension. Cognition 108(1): 51-68.

\section{Published Version}

http://dx.doi.org/10.1016/j.cognition.2007.12.012

\section{Permanent link}

http://nrs.harvard.edu/urn-3:HUL.InstRepos:3207706

\section{Terms of Use}

This article was downloaded from Harvard University's DASH repository, and is made available under the terms and conditions applicable to Other Posted Material, as set forth at http:// nrs.harvard.edu/urn-3:HUL.InstRepos:dash.current.terms-of-use\#LAA

\section{Share Your Story}

The Harvard community has made this article openly available.

Please share how this access benefits you. Submit a story.

\section{Accessibility}


Give and Take: Syntactic Priming during Spoken Language Comprehension

\author{
Malathi Thothathiri \\ Jesse Snedeker \\ Harvard University
}

Address correspondence to:

Malathi Thothathiri

Department of Psychology, Harvard University

William James Hall, 33 Kirkland Street

Cambridge, MA 02138

Ph: (617) 384-8357

Fax: (617) 384-7944

Email:malathi@wjh.harvard.edu 


\section{Abstract}

Syntactic priming during language production is pervasive and well-studied. Hearing, reading, speaking or writing a sentence with a given structure increases the probability of subsequently producing the same structure, regardless of whether the prime and target share lexical content. In contrast, syntactic priming during comprehension has proven more elusive, fueling claims that comprehension is less dependent on general syntactic representations and more dependent on lexical knowledge. In three experiments we explored syntactic priming during spoken language comprehension. Participants acted out double-object (DO) or prepositional-object (PO) dative sentences while their eye movements were recorded. Prime sentences used different verbs and nouns than the target sentences. In target sentences, the onset of the direct-object noun was consistent with both an animate recipient and an inanimate theme, creating a temporary ambiguity in the argument structure of the verb (DO e.g., Show the horse the book; PO e.g., Show the horn to the dog). We measured the difference in looks to the potential recipient and the potential theme during the ambiguous interval. In all experiments, participants who heard DO primes showed a greater preference for the recipient over the theme than those who heard PO primes, demonstrating across-verb priming during online language comprehension. These results accord with priming found in production studies, indicating a role for abstract structural information during comprehension as well as production. Keywords: Syntactic priming; Comprehension; Dative; Eye movements 
Several language production studies have shown that people tend to reuse previously used syntactic structures. For example, in a study by Bock (1986), adults were more likely to describe a picture using a prepositional-object dative (PO e.g., The girl handed a paintbrush to the man) after a PO description (e.g., The rock star sold some cocaine to an undercover agent). Similarly, they were more likely to use a double-object dative (DO e.g., The girl handed the man a paintbrush) after a DO description (e.g., The rock star sold an undercover agent some cocaine). Subsequent studies have established that this priming is structural, and not due to lexical or prosodic similarity alone (Bock, 1989; Bock \& Loebell, 1990). In addition to picture-description, priming has been demonstrated during written sentence completion, spoken sentence completion, and dialogue with a confederate (Branigan, Pickering \& Cleland, 2000; Branigan, Pickering, Stewart \& McLean, 2000; Pickering \& Branigan, 1998). These studies show that prior exposure to structural information, either through comprehension or production, influences adults’ subsequent production. These effects persist even when the verb in the prime sentence is different from that in the target sentence, indicating that abstract syntactic representations are used during language production. ${ }^{1}$

In contrast, the evidence for abstract syntactic priming during comprehension is weak. Using a grammatical judgment task, Luka \& Barsalou (2005) found increased acceptability ratings when syntactic structure was repeated. In an fMRI study, Noppeney \& Price (2004) found reduced reading time when participants read similar syntactic

\footnotetext{
${ }^{1}$ Throughout this paper, we use the word abstract to refer to syntactic information that is not specific to a particular verb. We have followed the common practice of calling this syntactic priming. However the precise nature of the representation that is activated is unclear. As we note in the General Discussion our experiments, like most of the prior studies, cannot distinguish between the activation of: abstract phrase structure (V NP PP), mappings between thematic roles and phrasal constituents (recipient $\rightarrow$ PP), and mappings between thematic roles and linear order (theme first, recipient second).
} 
forms. These results contrast with an expression-to-picture matching study that found priming when the same verb was used in prime and target sentences, but not when different verbs were used (Branigan, Pickering \& McLean, 2005. See also Pickering \& Traxler, 2004 and Traxler \& Pickering, 2005). These studies all share two limitations. First, none of them exclusively used semantically equivalent structures such as the dative alternation, so priming (when present) could have been semantic rather than syntactic. Second, these studies did not explore online processing, so it is unclear whether the priming effects relate to initial analysis or later reanalysis (Branigan, Pickering, Liversedge, Stewart \& Urbach, 1995).

Two recent eye-tracking studies looked for online evidence of priming during comprehension of semantically equivalent structures. Scheepers \& Crocker (2004) studied the processing of German transitive sentences with case-marking. They found that the online interpretation of ambiguously marked preverbal arguments was influenced by prior unambiguously marked prime sentences. In contrast, using the English dative alternation, Arai, Van Gompel \& Scheepers (2007) looked for priming of the interpretation of postverbal arguments. They found priming when prime and target sentences contained the same verb, but not when they contained different verbs.

The verb-specific priming results are consistent with lexicalist theories that propose that connections between verbs and their associated syntactic structures are tuned by prior exposure (e.g., MacDonald, Pearlmutter \& Seidenberg, 1994; Trueswell \& Tanenhaus, 1994). The variation in findings for abstract priming in many of the studies echoes prior debates about the relevance of coarse-grained structural information during language comprehension (Mitchell, Cuetos, Corley \& Brysbaert, 1995; Spivey-Knowlton \& 
Sedivy, 1995). Trying to synthesize contradictory findings, Mitchell, et al. (1995) suggested that fine-grained lexical information may play an important role in resolving verb argument ambiguities (where lexical constraints are common), while coarse-grained structural information may play an important role in resolving ambiguities such as relative clause attachment (where lexical constraints are not relevant). This provides one plausible explanation for why Arai and colleagues found evidence for lexically-specific but not abstract priming during the comprehension of postverbal ambiguities in argument structure. Alternatively, the lack of an abstract priming effect may be due to the specific task or stimuli parameters that were used.

In this article, we revisit the role of abstract structural information during the comprehension of verb argument ambiguities. We ask whether the online interpretation of a sentence after the verb is encountered, is guided entirely by verb-specific information, or whether it utilizes abstract syntactic representations that are implicated in language production. For ease of comparison, we use the semantically equivalent dative structures that are commonly employed in production-priming studies. The visual world eye-gaze paradigm is used to explore the timing of potential priming effects. Our paradigm differs in important ways from a similar study done by Arai, et al. (2007), which may increase our chances of finding across-verb priming (see General Discussion).

\section{Experiment I}

Using an act-out comprehension task, we investigated whether prior DO or PO dative sentences influenced the comprehension of subsequent dative sentences with different verbs. 


\section{Methods}

Twenty-eight native English speakers from the Boston area participated (7 in each experimental condition). Participants were seated in front of an inclined podium with four shelves. A camera was placed at a hole in the center of the podium and was focused on the participant's face (see Fig. 1). On each trial, the experimenter brought out four toys (2 animals and 2 inanimate objects), and placed one on each shelf while labeling them. The trial began with a command to look at the center followed by an instruction involving the toys. Participants were told to listen to the entire instruction before acting it out.

Each participant listened to four blocks of instructions pre-recorded by a female speaker. In each block, the first two sentences were fillers (non-datives). The next two were DO or PO prime dative sentences (e.g., DO: Send the frog the gift; PO: Send the gift to the frog). The last was a target $\mathrm{DO}$ or PO dative sentence that contained a temporary ambiguity (e.g., DO: Show the horse the book; PO: Show the horn to the dog). Hand, pass, feed and send were each used in two prime sentences in two different blocks. Throw and show were each used in two target sentences, yielding a total of four critical trials. Both prime and target type were manipulated between participants. Each participant was randomly assigned to one of the four possible conditions (prime-target: DO-DO; DO-PO; PO-DO; PO-PO). See Appendix for a sample block of instructions. The betweenparticipants design was employed to maximize the possibility of detecting priming effects. If priming is cumulative or long-lasting, then in a within-participants design the effect of a prime on one trial might cancel out the effect of another prime on the next. This interference is alleviated in a between-participants design where all prime sentences are of the same type for a given session. 


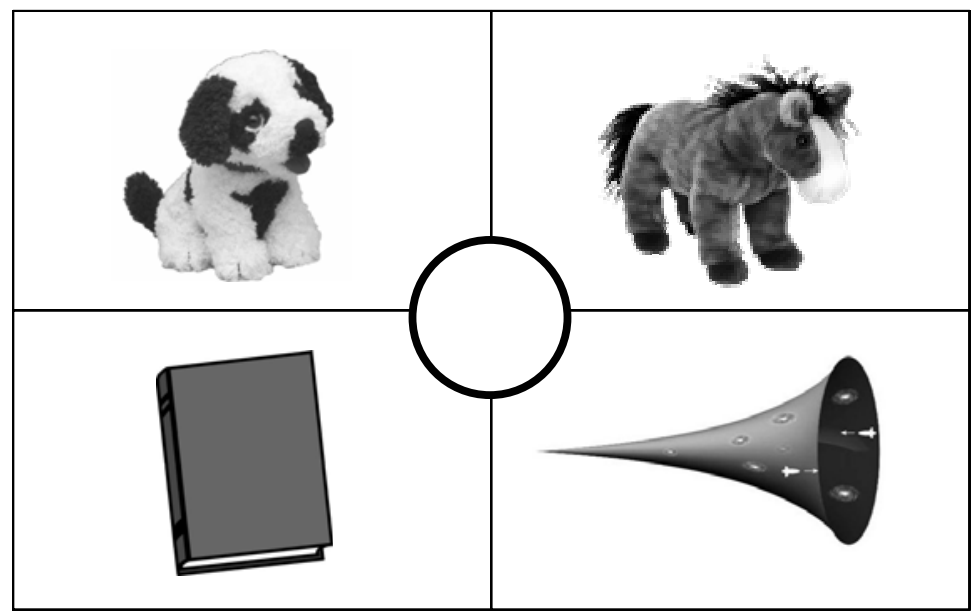

Figure 1. Schematic diagram of the setup for a trial. Eye movements were recorded by a camera placed behind the hole in the center. Target trials contained two items with similar phonological onsets (e.g., horse and horn).

\section{Coding}

Eye movements were recorded by the camera centered behind the display. They were coded as being to the center, away or to one of the four quadrants. If the eyes were not visible the frame was excluded from the analysis. All eye coding was done with the audio turned off. Ten percent of the trials were coded by a second coder. Intercoder reliability was 84\% (Cohen’s Kappa = 0.8).

\section{Dependent Measure}

We coded eye movements on target trials only. On these trials, there was an interval of ambiguity (e.g., Show the hor...). The visual scene included two items that were phonological matches to the initial part of the first noun - a possible animate recipient (e.g., horse) and a possible inanimate theme (e.g., horn) (See Fig. 1). We hereafter refer to these two items as animal and object respectively. A gating task given to two adults 
determined that the first noun was disambiguated an average of $400 \mathrm{~ms}$ after noun-onset. Since it takes about 200 ms to program an eye movement (Matin, Shao, \& Boff, 1993), our critical time interval began $200 \mathrm{~ms}$ after the onset of the first noun (e.g., hor...) and ended $400 \mathrm{~ms}$ later. We calculated looks to the animal and the object as a proportion of looks to all four items and the center. Because we were specifically interested in how much adults looked at the animal relative to the object, we computed a difference score (proportion of looks to animal minus proportion of looks to object). If comprehension depends exclusively on verb-specific information, we would expect no differences between prime conditions (because prime and target sentences used different verbs). In contrast, if abstract syntactic information is used in language comprehension, we would expect that in response to the first noun in target sentences (e.g., hor...), adults who heard DO prime sentences (e.g., Send the frog the gift) would look more at the potential recipient (an animal, e.g., horse), while those who heard PO prime sentences (e.g., Send the gift to the frog) would look more at the potential theme (an object, e.g., horn). Thus, difference scores would be higher in the DO-prime conditions than in the PO-prime conditions.

\section{Results}

Participants typically completed the action by moving an inanimate theme to a stationary recipient. They incorporated the manner of the transfer whenever applicable (e.g., a throwing motion in response to throw...). All the responses were accurate, indicating that the participants reached the correct interpretation of the utterance irrespective of the prime type. However, their eye movements during the period of ambiguity were affected by the prime. Figures 2 and 3 graph eye movements relative to the onset of the first noun 
for DO and PO targets respectively. ${ }^{2}$ Each figure compares a pair of conditions in which the target sentences are the same but the primes differ. Qualitatively, during the ambiguous interval for DO targets, we see that adults in the DO-prime condition were looking more at the animal (difference $>0$ ) while those in the PO-prime condition were looking more at the object (difference $<0$ ) (Fig. 2). Eye movements to PO targets show a similar pattern (Fig. 3). We computed an average difference score for each participant, excluding those trials where participants were looking away from the four items for more than two-thirds of the interval. In all experiments, this eliminated less than $5 \%$ of the trials. A 2x2 between-participants ANOVA (Prime Type x Target Type) revealed an effect of prime type $[\mathrm{F}(1,24)=4.459, \mathrm{p}<.05]$. As predicted, difference scores were higher in the DO-prime conditions ( $\mathrm{M}=0.178)$ than in the PO-prime conditions $(\mathrm{M}=$ 0.099; S.E. $=0.093)$. There were no other effects. ${ }^{3}$

\footnotetext{
${ }^{2}$ For simplicity, we only show looks to the critical animal and object. In all experiments, the sum of looks to the two non-critical items and the center did not vary across conditions (all p's $>0.3$ ).

${ }^{3}$ Because only four items were used, we present the participants' analysis as our primary statistic. But we also found a marginal effect of prime in an items ANOVA $[\mathrm{F}(1,3)=6.110, \mathrm{p}=.09]$. This marginal prime effect persisted in a non-parametric analysis that makes no assumptions about the distribution of variables [Wilcoxon signed ranks test, $\mathrm{p}=.068$ ].
} 


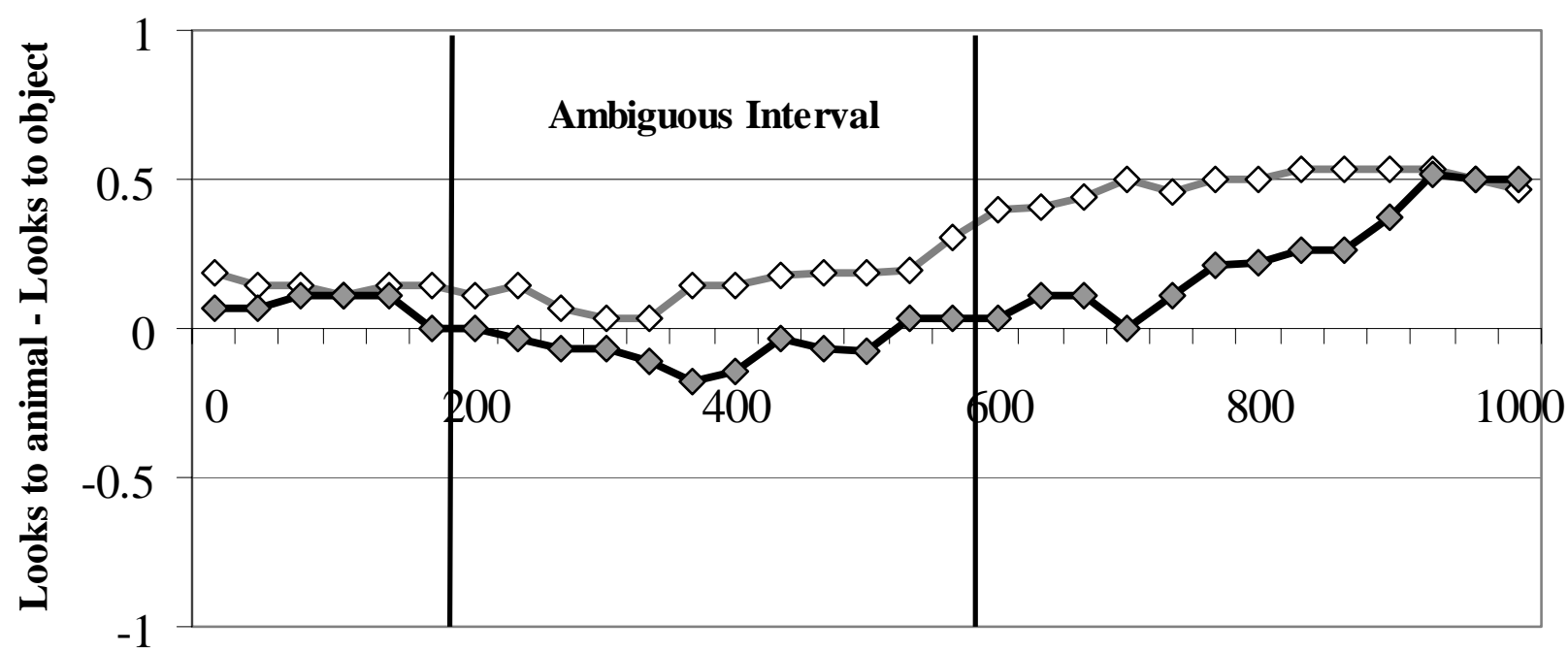

Time from Noun Onset (in milliseconds)

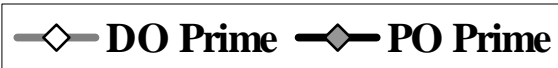

Figure 2. Difference in the proportion of looks to the animal and the object. Experiment I:

DO targets.

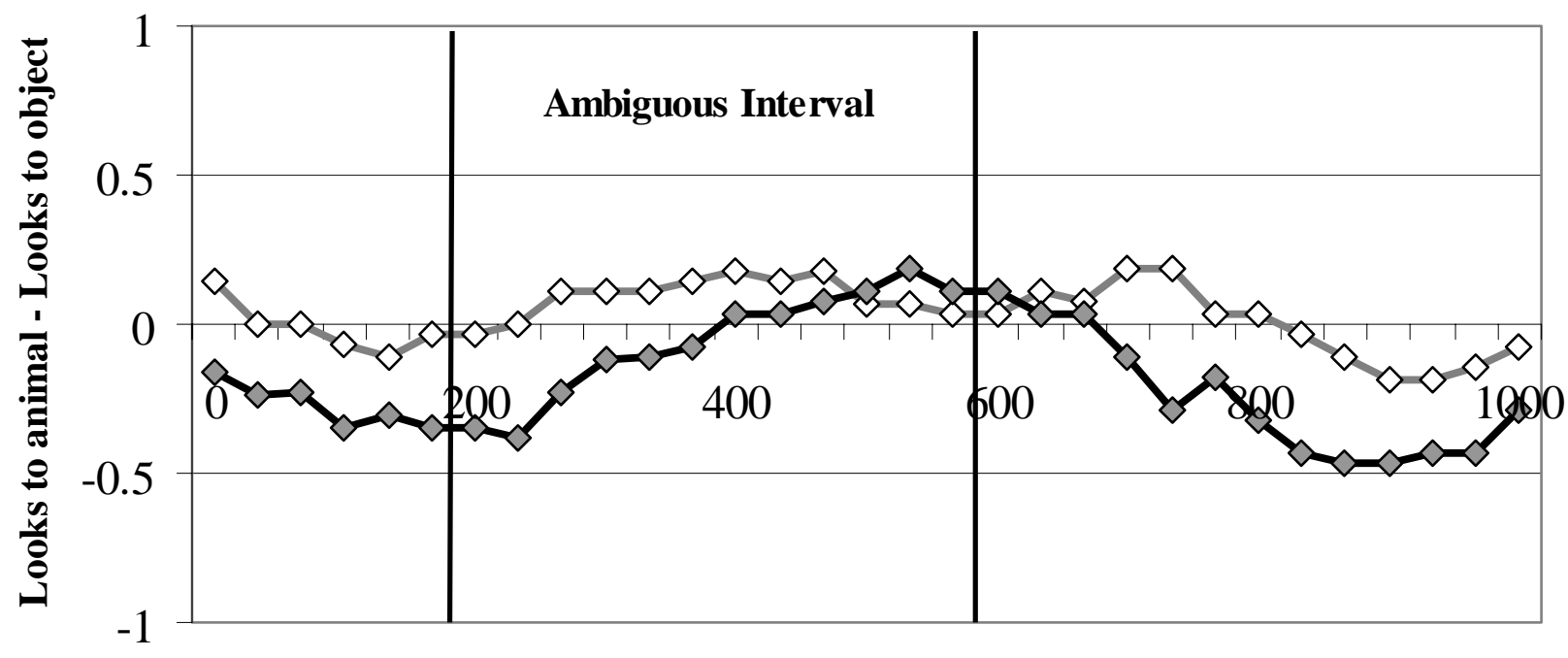

Time from Noun Onset (in milliseconds)

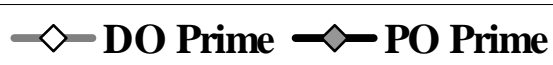

Figure 3. Difference in the proportion of looks to the animal and the object. Experiment I: PO targets. 
The prime and target sentences in this experiment used different verbs. Thus, these results suggest that abstract, non-verb-specific representations are used during online language comprehension. These findings contrast strongly with a prior comprehensionpriming study that found priming only when the verb was repeated (Arai, et al., 2007). That study used a passive viewing task, while our task required participants to plan and execute an action. Thus we considered the possibility that the locus of our priming effect was in the mapping from the utterance to the action plan. ${ }^{4}$ Experiment II explores whether abstract priming persists when prime sentences are not acted out or mapped onto a visual array. Participants passively listened to a story that contained the prime sentences and then acted out target sentences using a set of props. If priming persists under these conditions we can rule out the possibility that actions are critical to producing priming during comprehension. ${ }^{5}$

\footnotetext{
${ }^{4}$ The direct priming of action plans could not account for our findings. DO and PO primes always requested the same action and participants in both prime conditions appeared to execute them in the same way (typically by moving the object while the animal remained stationary).

${ }^{5}$ Of course this design leaves open the possibility that an action task is necessary to allow us to observe the effects of priming on processing the target utterance.
} 


\section{Experiment II}

\section{Methods}

Twenty-eight native English speakers from the Boston area participated (7 in each condition). The procedure was similar to Experiment I except that participants were told

that they were going to listen to two voices (Bob and Susan) from a computer; Bob would tell them stories about his life; Susan would give them instructions to act out. There were 14 pre-recorded trials. At the beginning of each trial, Bob’s voice talked about events that happened in a children's store the day before. Susan's voice then interrupted with “It's my turn. Are you ready?” followed by the actual instruction. The first three trials were fillers that did not involve dative sentences. Trials 4 to 14 alternated between targets and fillers, for a total of 6 critical target trials using the verbs bring, pass, throw, send, toss and hand. The prime verbs were read, teach, sing, show, sell and feed. Each prime verb was used twice, in two different trials. On target trials, Bob’s last two sentences were DO or PO dative primes. Susan's target instruction was also a DO or PO dative. As before, both prime and target type were manipulated between participants, thus participants were assigned to one of four conditions (DO-DO; DO-PO; PO-DO; PO-PO). See Appendix for example filler and target trials.

\section{Coding}

Ten percent of the trials were coded by a second coder. Intercoder reliability was $89 \%$ (Cohen’s Kappa = 0.86). 


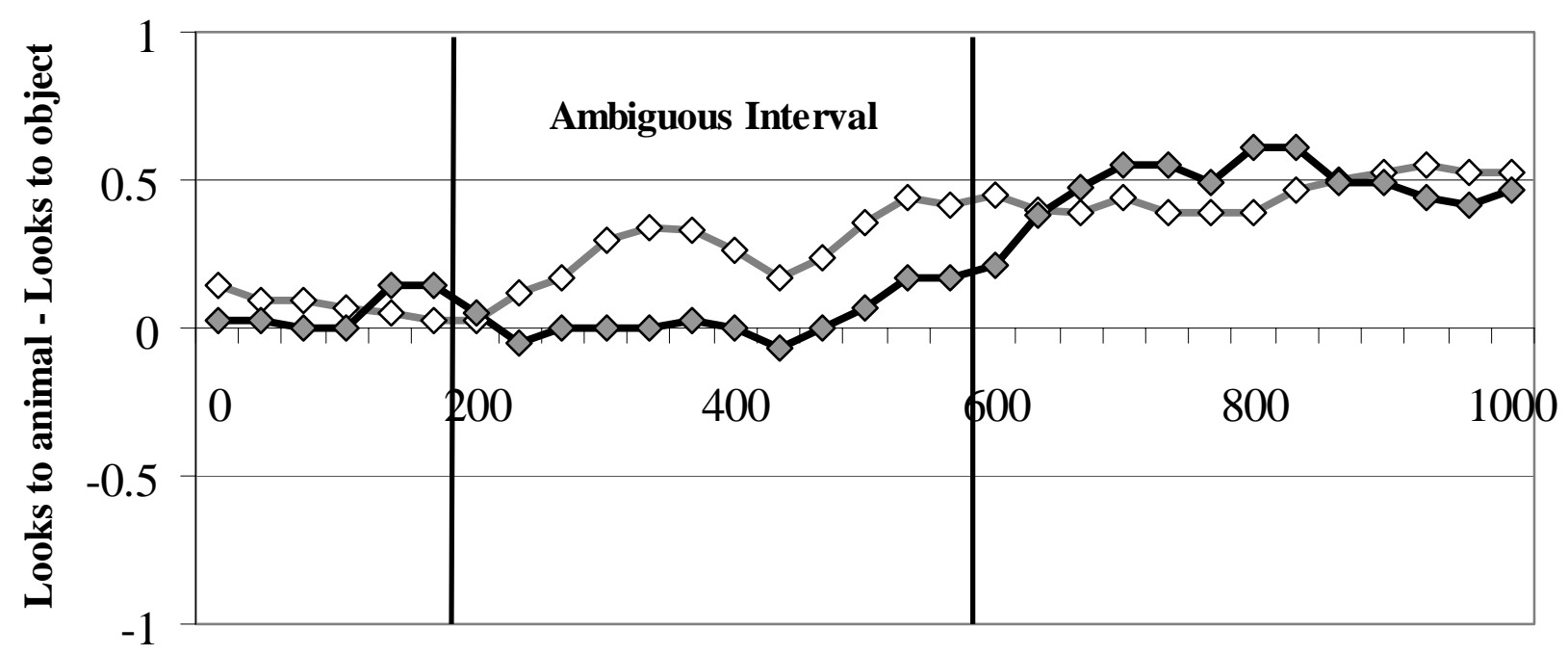

Time from Noun Onset (in milliseconds)

$\diamond$ DO Prime $\prec$ PO Prime

Figure 4. Difference in the proportion of looks to the animal and the object. Experiment II: DO targets.

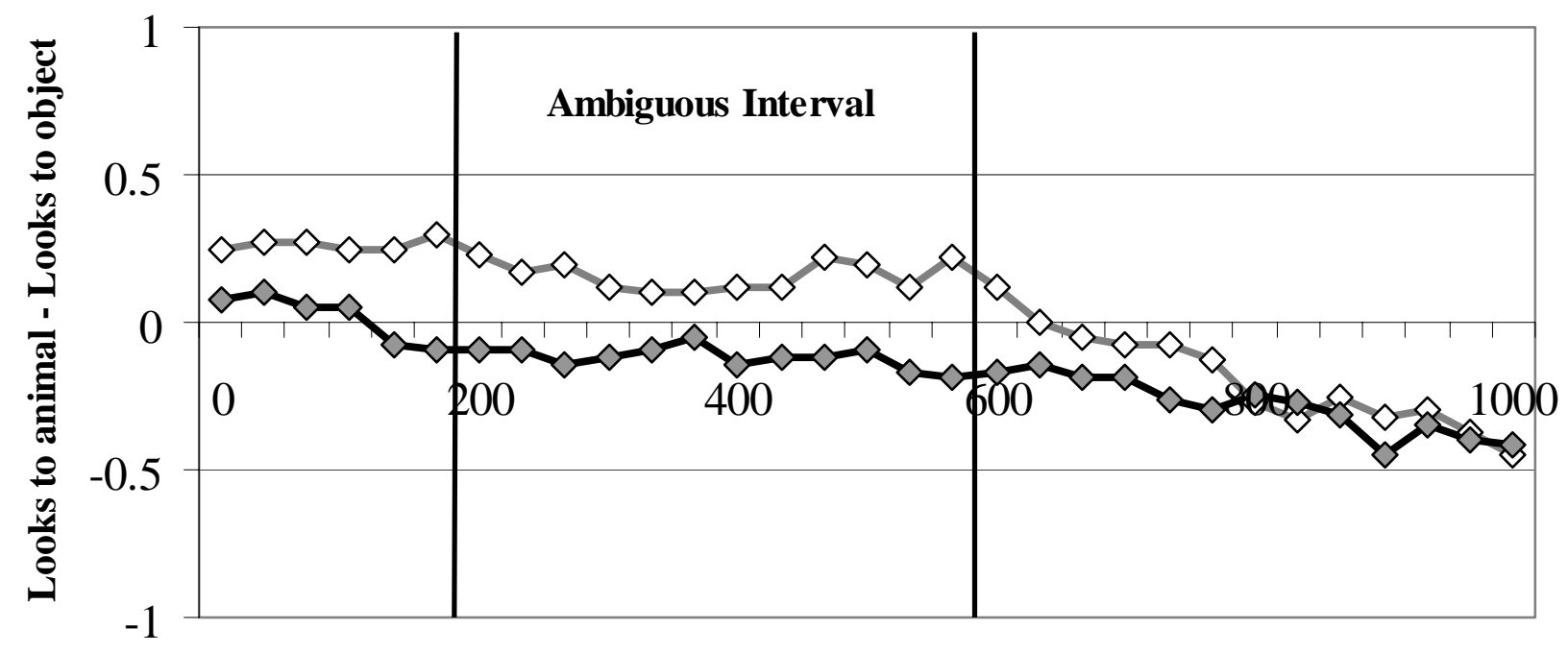

Time from Noun Onset (in milliseconds)

\section{$\diamond$ DO Prime $\prec$ PO Prime}

Figure 5. Difference in the proportion of looks to the animal and the object. Experiment II: PO targets. 


\section{Results}

Participants performed the right action on all target trials. Eye movements to DO and PO targets are shown in figures 4 and 5 respectively. Qualitatively, for DO targets, participants were looking at the animal more than the object in the DO-prime condition (difference $>0$ ), but not in the PO-prime condition (Fig. 4). For PO targets, they were looking more at the animal in the DO-prime condition (difference $>0$ ), and more at the object in the PO-prime condition (difference < 0) (Fig. 5). We analyzed eye movements in the same time window as before (200-600 ms from noun-onset). A 2x2 betweenparticipants ANOVA (Prime Type x Target Type) revealed an effect of prime type [F1(1, 24) $=6.927, \mathrm{p}<.02 ; \mathrm{F} 2(1,5)=13.102, \mathrm{p}<.02]$. As predicted, difference scores were higher in the DO-prime conditions $(\mathrm{M}=0.219)$ than in the PO-prime conditions $(\mathrm{M}=$ 0.041; S.E. = 0.07). There was also an effect of target type, marginally significant by items only $[\mathrm{F} 1(1,24)=1.488, \mathrm{p}>.2 ; \mathrm{F} 2(1,5)=4.736, \mathrm{p}=.081]$. Difference scores were higher in the DO-target conditions $(\mathrm{M}=0.149)$ than in the PO-target conditions $(\mathrm{M}=$ 0.028; S.E. $=0.07)$. Because of the small number of items and the possible violation of normality, we also conducted non-parametric analyses of the data. The prime effect was still significant [participants analysis: Mann-Whitney test, $\mathrm{p}<.02$; items analysis: Wilcoxon signed ranks test, $\mathrm{p}<.05]$.

In this experiment, participants passively listened to prime sentences and did not act them out. Furthermore, prime and target sentences were spoken by different speakers. In a post-experiment questionnaire, only two participants surmised that the sentences spoken by the two speakers might be related. These results suggest that the comprehension-to-comprehension priming found here is not due to explicit attention to 
the similarities between prime and target sentences or due to the priming of action-related strategies.

Our findings diverge from those of previous studies on postverbal structural priming during comprehension: while we find clear evidence of abstract priming, others have found only verb-specific priming (Arai, et al., 2007; Branigan, et al., 2005). One possibility is that the difference stems from features of our experimental design. While prior studies followed the standard practice in adult psycholinguistics and employed within-participants designs, we chose to use a between-participants design (which is more common in developmental psychology). This choice may have been critical. As we noted above, between-participants designs are less vulnerable to interference effects and thus may magnify small effects by allowing them to summate over trials. This possibility is consistent with theories that link structural priming to implicit learning and with prior studies demonstrating that production priming persists over long intervals (Bock \& Griffin, 2000) and can accumulate over several trials (Kaschak, Loney \& Borreggine, 2006). The existence of cumulative and/or long-lasting effects does not undermine our primary claim that abstract priming occurs during comprehension. However, it would alter our understanding of this phenomenon. If comprehension priming only occurs when prime type is stable across trials, that would suggest that the mechanism is quite different from the one that underlies production priming, which can occur after a single prime in a within-participants design.

The use of a between- participants design also raises the possibility that the observed priming effects are the result of deliberate strategies specific to the experimental task. In our design primes outnumbered targets two to one. Consequently the most common type 
of dative was the prime type. If participants became aware of this and adjusted their expectations accordingly, they could adopt a strategy of assuming that all dative utterances would be of this type. We find this possibility unlikely — participants did not report awareness of the prime manipulation and priming was equally robust in Experiment II even though the contexts of the prime and target sentences were quite different. Nevertheless it highlights the importance of determining whether abstract priming persists when the prime type is not consistent across trials. In Experiment III, we explored this question by manipulating prime and target type within participants. In addition we increased the number of critical items in this experiment to determine whether priming generalizes to a wider array of dative verbs. 


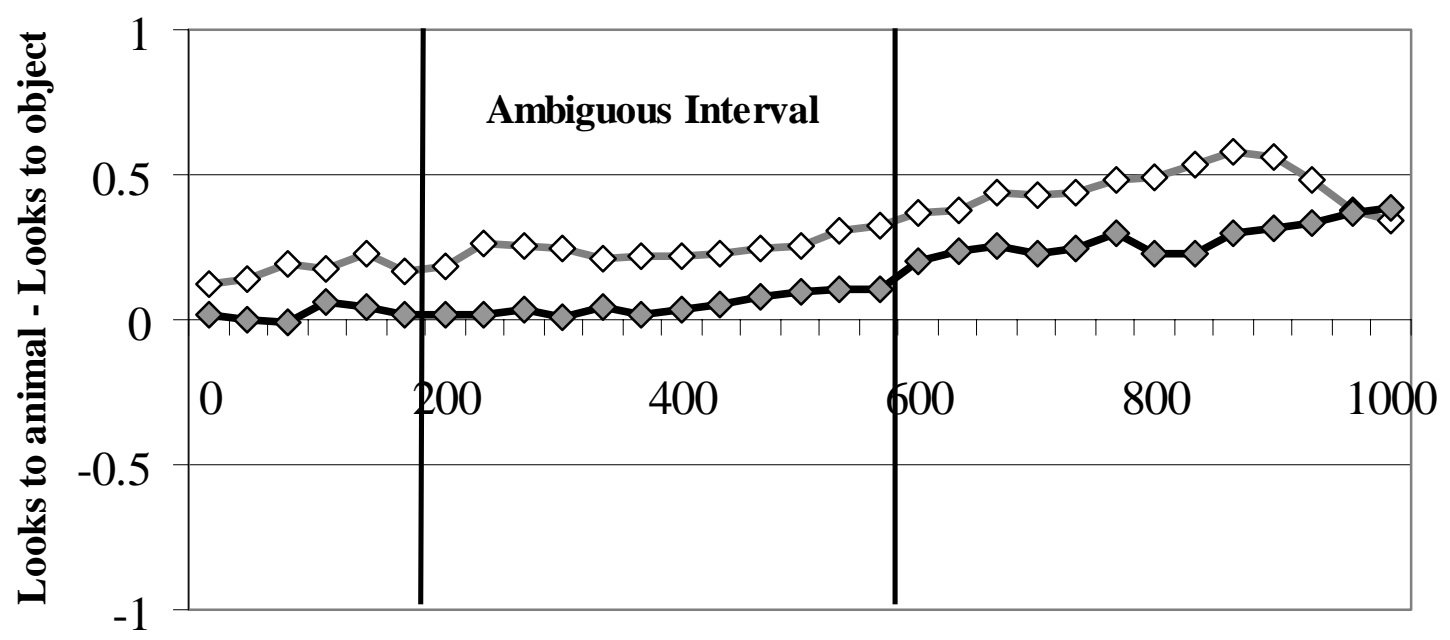

Time from Noun Onset (in milliseconds)

$\diamond$ DO Prime $\prec$ PO Prime

Figure 6. Difference in the proportion of looks to the animal and the object. Experiment III: DO targets.

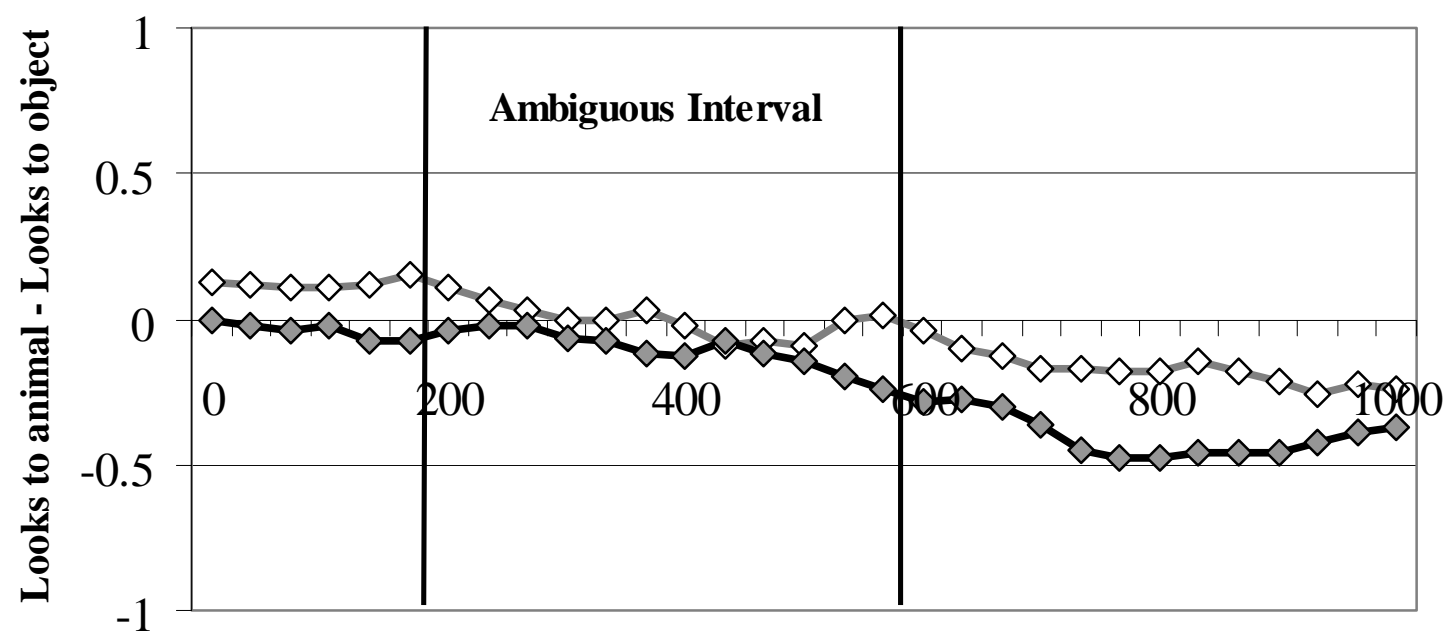

Time from Noun Onset (in milliseconds)

$$
\diamond \text { DO Prime } \prec \text { PO Prime }
$$

Figure 7. Difference in the proportion of looks to the animal and the object. Experiment III: PO targets. 


\section{Experiment III}

\section{Methods}

Twenty-four native English speakers from the Boston area participated. Three other adults were tested but excluded due to: video-recording error (1), lack of eye movements during the ambiguous interval because the participant tended to look at the center of the display (1), and awareness of the experimental manipulation as indicated by a postexperimental questionnaire (1). The procedure was similar to Experiment II. A male speaker narrated stories about several, unrelated people. On critical trials, the stories

contained two prime sentences at the end. Subsequently, a female speaker spoke the instruction to be acted out. The critical difference from Experiment II was that both prime and target type were manipulated within participants. Each session consisted of 24 filler trials and 16 critical trials. There were 8 different prime verbs: sell, sing, teach, read, fax, mail, rent and write. The prime verbs were randomly paired to yield 16 unique pairs, one for each critical trial. There were 12 different target verbs: bring, pass, hand, send, throw, toss, give, show, offer, feed, lend and take. Four of these (bring, pass, hand, give) were repeated to yield a total of 16 target sentences. See Appendix for example filler and target trials and a complete list of prime verbs and target sentences.

Prime pairs were arbitrarily matched with targets to make the critical items. Four versions of each item were created by crossing the prime type and target type (DO prime - DO target, DO prime - PO target, PO prime - DO target, PO prime - PO target). Four lists were constructed in the standard fashion such that each list contained just one version of every item and all four versions of a given item appeared across lists. Each 
participant heard four of each possible combination of prime and target types. The 16 critical trials were interspersed with 24 filler items in a quasi-random order with the constraint that targets be separated by at least one but not more than two filler items. A second order was constructed by reversing the first order. Participants were assigned to one of the four lists and two orders.

\section{Coding}

Ten percent of the trials were coded by a second coder. Intercoder reliability was $92 \%$ (Cohen's Kappa = 0.9).

\section{Results}

Participants performed the right action on all target trials. Eye movements to DO and PO targets are shown in figures 6 and 7 respectively. Qualitatively, for DO targets, participants were looking at the animal more than the object in the DO-prime trials (difference > 0), but not in the PO-prime trials (Fig. 6). For PO targets, they were looking equally at the animal and the object in the DO-prime trials (difference $=0$ ), and more at the object in the PO-prime trials (difference < 0) (Fig. 7). These results were confirmed by the statistical analyses. There were no list or order effects, so we report analyses using the prime and target type factors only. We analyzed eye movements between 200 to 600 ms after the onset of the noun, just as before. A 2x2 within-participants ANOVA revealed a significant effect of prime type $[\mathrm{F} 1(1,23)=8.602, \mathrm{p}<.01 ; \mathrm{F} 2(1,15)=5.988, \mathrm{p}<.03] .{ }^{6}$ As predicted, difference scores were higher in the DO-prime trials $(\mathrm{M}=0.124)$ than in the PO-prime trials ( $M=-0.025 ;$ S.E. $=0.04)$. In addition, there was an effect of target type

\footnotetext{
${ }^{6}$ As in Experiment II, non-parametric tests also revealed a significant effect of prime [participants analysis: Wilcoxon signed ranks test, $\mathrm{p}<.01$; items analysis: Wilcoxon signed ranks test, $\mathrm{p}<.03$ ].
} 
$(F 1(1,23)=12.396, \mathrm{p}<.01 ; \mathrm{F} 2(1,15)=10.828, \mathrm{p}<.01)$. Difference scores were higher in the DO-target trials $(M=0.143)$ than in the PO-target trials $(M=-0.044$; S.E. $=0.04)$, suggesting that disambiguation of the target noun occurred prior to $400 \mathrm{~ms}$ from nounonset. There was no interaction between the two factors.

In this experiment, we manipulated prime type within participants. Each target sentence was preceded by just two prime sentences, comparable to some productionpriming studies (e.g., Pickering \& Branigan, 1998). Thus, these priming effects show that abstract priming during comprehension does not depend on extensive exposure to the primed structure and is not based on a deliberate strategy of adjusting expectations according to the relative frequency of each sentence type. We discuss the implications of this finding and possible differences from previous comprehension-priming studies in General Discussion. 


\section{General Discussion}

The three experiments reported here demonstrate comprehension-to-comprehension priming in adults even when different verbs are used in prime and target sentences. They extend the findings from previous studies (Luka \& Barsalou, 2005; Noppeney \& Price, 2004) in two ways. First, we used semantically equivalent dative sentences thereby minimizing the possibility that priming was semantic rather than syntactic. Second, we found that priming unfolds soon after the onset of the first noun, which was on average less than 600 ms after verb-onset (M=542 ms, 547 ms and 567 ms for Experiments I, II and III respectively). The time course suggests that priming influences the initial syntactic analysis of the postverbal arguments. These results also complement Scheepers \& Crocker (2004) by showing syntactic priming during the interpretation of postverbal arguments. Abstract, non-verb-specific information appears to influence comprehension even after a specific verb has been encountered.

Our results contrast with a recent study that did not find abstract priming during the comprehension of datives (Arai, et al., 2007). It is unlikely that this discrepancy is due to differences in the verbs or the eye-tracking procedure. In this and other studies (Thothathiri \& Snedeker, 2006), we have shown priming using a variety of verbs that overlap with the ones used by Arai and colleagues. The two eye-tracking methodologies used (hidden camera and head-mounted) have been shown to produce similar results (Snedeker \& Trueswell, 2004).

We next considered the possibility that differences in the time windows for the analyses may be responsible for the discrepancy. Arai and colleagues looked for priming effects prior to the onset of the first postverbal noun while we looked for effects 
subsequent to noun-onset. Perhaps initial processing of verbs during comprehension is lexically-specific while later integration processes depend on abstract structural information. The elapsed time from verb onset is unlikely to account for the divergence in findings: our priming effects emerge around noun-onset less than $600 \mathrm{~ms}$ after the onset of the verb (e.g., fig. 6 and 7), which is approximately the same time at which the within-verb priming effects appear in the Arai, et al. study (600-900 ms after verb-onset). The two studies however, differed in the type of information that was available during this time: in our study this early window coincided with the onset of the direct-object noun, in theirs it preceded the determiner and presumably coincided with the end of the verb. ${ }^{7}$ Since nouns are critical for determining reference their onset may trigger more eye-movements to the predicted referent, increasing our ability to detect priming effects. To explore this possibility we re-examined the data from Experiment III to determine if the priming effects emerged prior to the noun. We analyzed the interval between the onset of the verb (with a $200 \mathrm{~ms}$ offset for the programming and execution of eye movements) and the onset of the noun. This resulted in a $400 \mathrm{~ms}$ window (200-600 ms after verb onset). Because this window preceded any phonological information about the noun, we compared looks to both animals and both objects instead of focusing on just the critical items. A 2x2 ANOVA revealed no main effect of prime (p’s > .6). Difference scores in the DO-prime conditions $(\mathrm{M}=0.083$ ) were not significantly higher than those in the PO-prime conditions $(\mathrm{M}=0.054$; S.E. $=0.052)$. But there was a significant

\footnotetext{
${ }^{7}$ The two studies may also differ in the prosody of the target utterances. In our study, there was never an intonational phrase break after the verb. In contrast, the average interval between the onset of the verb and the onset of the postverbal determiner in Arai, et al. ( $\sim 900 \mathrm{~ms}$ compared to $\sim 400 \mathrm{~ms}$ in our studies) suggests that their stimuli may contain a break after the verb. Such a break, if present, may lead participants to expect that the verb phrase is complete or that the next constituent is long and complex (see Kjelgaard \& Speer, 1999; Speer, Kjelgaard \& Dobroth, 1996; Watson \& Gibson, 2004), thereby disfavoring both DO and PO structures containing short NPs.
} 
interaction between prime type and target type $[\mathrm{F} 1(1,23)=5.618, \mathrm{p}<.03 ; \mathrm{F} 2(1,15)=$ 9.874, $\mathrm{p}<.01]$. There was an effect of prime for DO targets, significant by items and marginally significant by participants $[\mathrm{F} 1(1,23)=4.13, \mathrm{p}=.054 ; \mathrm{F} 2(1,15)=5.754$, $\mathrm{p}<.04]$. As predicted, difference scores were higher in the DO-prime conditions ( $\mathrm{M}=$ 0.151, S.E. $=0.057)$ than in the PO-prime conditions $(\mathrm{M}=-0.07$, S.E. $=0.079)$. This early effect is consistent with prior studies that show anticipatory looks to possible arguments based on the processing of the verb (Altmann \& Kamide, 1999; Boland, 2005). There was no corresponding priming effect for PO targets $[\mathrm{F} 1(1,23)=1.77$, $\mathrm{p}>0.1 ; \mathrm{F} 2(1,15)=1.321, \mathrm{p}>0.2]$. The two types of target sentences were not matched acoustically, so prosodic differences may account for these differences. The presence of a priming effect for DO targets, prior to the onset of the noun, casts doubt on timing differences being the main source of discrepancy between our studies and prior studies of dative comprehension priming. However the fact that the priming effect is much weaker in this analysis and emerges only for DO targets suggests that our use of nouns with onset ambiguities increased our ability to detect priming effects. ${ }^{8}$

Three other differences between the studies may also help explain these divergent findings. First, the tasks themselves are quite different. Experiments II and III ruled out the possibility that priming was solely due to similarity of action plans between primes and targets in our act-out task. However, it is still possible that the deployment of eye movements in an act-out task is more sensitive to abstract structural information than the passive viewing task used by Arai and colleagues. Second, Arai, et al. used a single prime before each target trial while we used two. Previous evidence suggests that encountering

\footnotetext{
${ }^{8}$ This claim is further supported by a similar analysis in the pre-noun window for Experiment II, which revealed numerically higher difference scores for DO-prime over PO-prime conditions but no significant effect of prime or interaction.
} 
multiple verbs in a structure leads to stronger priming (Pickering \& Branigan, 1998; Savage, Lieven, Theakston \& Tomasello, 2006). Thus, the across-verb priming effect may have been too weak to detect in that study. Third, due to the interactive nature of our task, the prime and target sentences in our study were separated by at least one unrelated sentence (e.g., OK, are you ready? or Here comes Susan). This was not the case in the Arai, et al. study. Konopka \& Bock (2005) found that within-verb priming effects were strongest when there were no intervening trials between prime and target sentences. They attribute the within-verb effect to an explicit memory trace for the prime sentence which decays rapidly. In contrast, between-verb priming actually increased when there was an intervening trial between the prime and the target, suggesting that priming across verbs involves a very different process. For example, it could involve a form of implicit learning, parallel to the setting of connection weights in a neural network (Chang, Dell \& Bock, 2006). Thus our paradigm may have accentuated abstract priming and eliminated within-verb priming while the paradigm used by Arai and colleagues may have accentuated within-verb priming. This difference, in combination with a decrease in sensitivity (because of the task or the nature of the ambiguous region), might explain why the Arai study was able to detect a within verb priming effect but no effect of abstract priming. This speculative account needs to be validated by future studies of the precise influence of intervening linguistic material on non-verb-specific priming. ${ }^{9}$

By using semantically equivalent structures we ruled out the possibility that these priming effects reflect the activation of conceptual or semantic representations.

\footnotetext{
${ }^{9}$ An explanation based solely on the temporal gap between prime and target sentences is unlikely to account for the discrepancy between the two studies. In Experiment III, the temporal interval between prime and target sentences was between 1 and 2 seconds, a delay that is comparable to the one in Arai, et al. ( 1.2 seconds).
} 
Nevertheless, these effects, like those in prior production studies, could be driven by priming of several kinds of representations.

One possibility is that we primed the syntactic structures of double-object (Verb Noun-Phrase Noun-Phrase) and prepositional-object (Verb Noun-Phrase PrepositionalPhrase) datives (Pickering \& Branigan, 1998). These structures might activate the thematic roles associated with them, which in turn might activate the animacy features associated with those roles, resulting in the observed eye-movements. A second possibility is that we primed the mapping between thematic roles and syntactic positions (Chang, Bock, \& Goldberg, 2003). For example, double-object primes might activate a recipient $\leftrightarrow \rightarrow$ direct object mapping, while prepositional-object primes might activate a theme $\leftarrow \rightarrow$ direct object mapping. Since the recipient is usually animate and the theme is usually inanimate, this would give rise to the pattern of eye movements seen in our experiments.

A third possibility is priming of the mapping between animacy features and syntactic positions. Double-object and prepositional-object datives may have primed an animate $\leftrightarrow \rightarrow$ direct object and an inanimate $\leftarrow \rightarrow$ direct object mapping respectively. Using active and passive constructions, Bock, Loebell and Morey (1992) showed that priming can target the direct binding of animacy to sentential positions independent of the effect of syntactic structure. The most primitive version of this hypothesis is that priming involves simple rules linking animacy features to linear order (representations like “animate comes first”). Such a mechanism need not invoke the phrase structure of the utterance or the argument structure of the verb. Our recent work with children leads us to reject this possibility (Thothathiri \& Snedeker, in press). We found that while three-year- 
olds do show animacy priming between simple transitive sentences, this priming does not extend from datives to transitives. We concluded that either 1) animacy priming is not linked to linear order (+animate can be primed, but “animate goes first” cannot) or 2) that generalizations invoking both animacy and linear order are constrained to verbs from the same class or with similar thematic role assignments. If three-year-olds exhibit this level of syntactic sophistication, parsimony suggests that adults will as well. However, this possibility remains to be tested.

To summarize, there are three kinds of explanations that could lead to the priming effect shown here. All three of these forms of priming have been found in adults during sentence production (syntactic structures: Bock \& Loebell, 1990; animacy mappings: Bock, et al., 1992; thematic role mappings: Chang, et al., 2003) and they all invoke syntax - in the form of phrase structure or mappings between semantic/conceptual features and linear/hierarchical positions. At issue is the nature of the representations that are primarily targeted in this paradigm. Are they direct mappings between syntax and animacy, syntax-semantics correspondences, or structures that are purely syntactic? Future studies can explore this question by manipulating the semantics, syntax and animacy features of prime and target sentences. For example, would prepositional sentences with animate themes (e.g., she carried the girl to the store) prime DO datives because of the animate $\leftrightarrow \rightarrow$ direct object mapping, or PO datives due to the similarity in phrase structure and syntax-semantics correspondences?

In this paper, we have presented evidence for non-verb-specific priming during the online comprehension of datives. This evidence suggests that abstract structural information is used during comprehension as well as production. 


\section{Acknowledgments}

We thank Aditi Balakrishna for her tireless assistance in coding the eye movement data.

\section{Appendix}

\section{Experiment I: Sample block}

1. Scratch the soap.

2. Now tickle the bear.

3. Feed the zebra the candy / Feed the candy to the zebra.

4. Send the frog the gift / Send the gift to the frog.

5. Show the horse the book / Show the horn to the dog.

\section{Experiment II: Sample filler trial}

Bob: Hello, my name is Bob. I work in a children's store. We have a lot of books and toys in the store and play with all the children who come there.

Susan: It’s my turn. Are you ready?

Now you can tickle the zebra. Next, swing the sock.

\section{Experiment II: Sample target trial}

Bob: The boy at the store woke up after a nap and wanted to hear a story. The girl was getting sleepy. So I sang the girl a lullaby / sang a lullaby to the girl. Then I read the boy a story / read a story to the boy.

Susan: It's my turn. Are you ready?

Now you can send the horse the bottle / send the horn to the frog. 


\section{Experiment III: Sample filler trial}

Bob: Chris was running to class one day when he bumped into his old friend Joe. Initially they were too surprised to react. But after a while, they laughed and hugged one another.

Susan: Now you can wave the flag. Next poke the hippo.

\section{Experiment III: Sample target trial}

Bob: John’s 2-year-old daughter's birthday was coming up soon. His secretary went to the bookstore to look for children’s books. There a nice bookstore clerk sold the secretary a book / sold a book to the secretary. That night, John read his daughter a story / read a story to his daughter.

Susan: Now you can give the leopard the sock / give the letter to the bird.

\section{Experiment III: Critical items}

\begin{tabular}{|l|l|l|}
\hline $\begin{array}{l}\text { Item } \\
\#\end{array}$ & $\begin{array}{l}\text { Prime verb } \\
\text { pair }\end{array}$ & Target sentence \\
\hline 1. & sell, read & Now you can give the leopard the sock / give the letter to the bird \\
\hline 2. & rent, mail & Now you can feed the goat the pen / feed the gold to the bug \\
\hline 3. & fax, write & Now you can throw the rat the shoe / throw the rattle to the duck \\
\hline 4. & teach, sing & Now you can pass the tiger the cup / pass the tie to the whale \\
\hline 5. & read, mail & Now you can pass the dolphin the crayon / pass the dollar to the zebra \\
\hline 6. & teach, fax & Now you can show the cat the flag / show the can to the moose \\
\hline 7. & rent, sing & Now you can toss the penguin the stick / toss the pencil to the rooster \\
\hline 8. & sell, write & Now you can bring the cheetah the egg / bring the cheese to the hippo \\
\hline 9. & sell, mail & Now you can hand the lion the spoon / hand the lighter to the donkey \\
\hline 10. & rent, read & Now you can send the panda the truck / send the pants to the rhino \\
\hline 11. & fax, sing & Now you can take the horse the apple / take the horn to the dog \\
\hline 12. & teach, write & Now you can give the camel the brush / give the camera to the shark \\
\hline 13. & teach, read & Now you can bring the pig the hat / bring the pillow to the sheep \\
\hline 14. & mail, fax & Now you can lend the cow the shell / lend the couch to the bear \\
\hline 15. & sell, rent & Now you can offer the monkey the flower / offer the money to the kangaroo \\
\hline
\end{tabular}


\begin{tabular}{|l|l|l|l}
\hline 16. & sing, write & Now you can hand the eagle the fork / hand the easel to the bunny
\end{tabular} 


\section{References}

Altmann, G. T. M., \& Kamide, Y. (1999). Incremental interpretation at verbs: Restricting the domain of subsequent reference. Cognition, 73(3), 247-264.

Arai, M., Van Gompel, R. P. G., \& Scheepers, C. (2007). Priming ditransitive structures in comprehension. Cognitive Psychology, 54, 218-250.

Bock, J. K. (1986). Syntactic persistence in language production. Cognitive Psychology, $18,355-387$.

Bock, J. K. (1989). Closed class immanence in sentence production. Cognition, 31, 163186.

Bock, K., \& Loebell, H. (1990). Framing sentences. Cognition, 35, 1-39.

Bock, K., \& Griffin, Z. M. (2000). The persistence of structural priming: transient activation or implicit learning? Journal of Experimental Psychology: General, 129(2), 177-192.

Bock, K., Loebell, H., \& Morey, R. (1992). From conceptual roles to structural relations: bridging the syntactic cleft. Psychological Review, 99, 150-171.

Boland, J. (2005). Visual Arguments. Cognition, 95, 237-274.

Branigan, H. P., Pickering, M. J., \& Cleland, A. A. (2000). Syntactic co-ordination in dialogue. Cognition, 75, B13-25.

Branigan, H. P., Pickering, M. J., Stewart, A. J., \& McLean, J. F. (2000). Syntactic priming in spoken production: Linguistic and temporal interference. Memory \& Cognition, 28(8), 1297-1302.

Branigan, H. P., Pickering, M. J., \& McLean, J. F. (2005). Priming prepositional-phrase attachment during comprehension. Journal of Experimental Psychology: Learning, 
Memory \& Cognition, 31(3), 468-481.

Branigan, H. P., Pickering, M. J., Liversedge, S. P., Stewart, A. J., \& Urbach, T. P. (1995). Syntactic priming: Investigating the mental representation of language. Journal of Psycholinguistic Research, 24(6), 489-506.

Chang, F., Dell, G. S., \& Bock, K. (2006). Becoming syntactic. Psychological Review, 113(2), 234-272.

Chang, F., Bock, K., \& Goldberg, A. E. (2003). Can thematic roles leave traces of their places? Cognition, 90, 29-49.

Kaschak, M. P., Loney, R. A., \& Borreggine, K. L. (2006). Recent experience affects the strength of structural priming. Cognition, 99, B73-B82.

Kjelgaard, M. M., \& Speer, S. R. (1999). Prosodic facilitation and interference in the resolution of temporary syntactic closure ambiguity. Journal of Memory and Language, 40, 153-194.

Konopka, A., \& Bock, K. (2005). Helping syntax out: How much do words do? Paper presented at the 18th Annual CUNY Conference on Human Sentence Processing, Tucson, AZ.

Luka, B. J., \& Barsalou, L. W. (2005). Structural facilitation: Mere exposure effects for grammatical acceptability as evidence for syntactic priming in comprehension. Journal of Memory and Language, 52, 436-459.

MacDonald, M. C., Pearlmutter, N. J., \& Seidenberg, M. S. (1994). The lexical nature of syntactic ambiguity resolution. Psychological Review, 101(4), 676-703.

Matin, E., Shao, K. C., \& Boff, K. R. (1993). Saccadic overhead: Information-processing time with and without saccades. Perception \& Psychophysics, 53, 372-380. 
Mitchell, D. C., Cuetos, F., Corley, M. M. B., \& Brysbaert, M. (1995). Exposure-based models of human parsing: Evidence for the use of coarse-grained (nonlexical) statistical records. Journal of Psycholinguistic Research, 24(6), 469-488.

Noppeney, U., \& Price, C. J. (2004). An fMRI study of syntactic adaptation. Journal of Cognitive Neuroscience, 16, 702-713.

Pickering, M. J., \& Branigan, H. P. (1998). The representation of verbs: Evidence from syntactic priming in language production. Journal of Memory \& Language, 39, 633651.

Pickering, M.J., \& Traxler, M.J. (2004). Grammatical repetition and garden-path effects. Paper presented at the $17^{\text {th }}$ Annual CUNY Conference on Human Sentence Processing, College Park, MD.

Savage, C., Lieven, E., Theakston, A., \& Tomasello, M. (2006). Structural priming as implicit learning in language acquisition. Language Learning \& Development, 2(1), 27-49.

Scheepers, C., \& Crocker, M. W. (2004). Constituent order priming from reading to listening: A visual-world study. In M. Carreiras and C. J. Clifton (Eds.), The On-line Study of Sentence Comprehension: Eyetracking, ERP and Beyond (pp. 167-185). Hove: Psychology Press.

Snedeker, J., \& Trueswell, J. C. (2004). The developing constraints on parsing decisions: The role of lexical-biases and referential scenes in child and adult sentence processing. Cognitive Psychology, 49, 238-299.

Speer, S. R., Kjelgaard, M. M., \& Dobroth, K. M. (1996). The influence of prosodic structure on the resolution of temporary syntactic closure ambiguities. Journal of 
Psycholinguistic Research, 25, 249-271.

Spivey-Knowlton, M., \& Sedivy, J. C. (1995). Resolving attachment ambiguities with multiple constraints. Cognition, 55, 227-267.

Thothathiri, M., \& Snedeker, J. (2006). Structural priming during comprehension of datives. Poster presented at the 19th Annual CUNY Conference on Human Sentence Processing, New York, NY.

Thothathiri, M., \& Snedeker, J. (in press). Syntactic priming during language comprehension in three- and four-year-old children. Journal of Memory and Language.

Traxler, M. J., \& Pickering, M.J. (2005). Syntactic priming in comprehension: Evidence from eye-movements. Paper presented at the 18th Annual CUNY Conference on Human Sentence Processing, Tucson, AZ.

Trueswell, J. C., \& Tanenhaus, M. K. (1994). Toward a lexicalist framework of constraint-based syntactic ambiguity resolution. In Clifton \& Frazier (Eds.), Perspectives on sentence processing. Hillsdale, NJ: Erlbaum.

Watson, D., \& Gibson, E. (2004). The relationship between intonational phrasing and syntactic structure in language production. Language and Cognitive Processes, 19, 713-755. 